\section{Discussion}

Patients admitted to casualty departments with acutely disturbed behaviour present a major diagnostic challenge. The differential diagnosis includes both primary psychiatric illness and a wide range of organic acute brain syndromes, including substance abuse.

Certain toxic syndromes indicating a specific substance may become familiar to medical staff owing to frequent local abuse. An infusion of $B$ sauveolens, regularly used in the Brisbane region, causes a central anticholinergic syndrome with wildly disturbed behaviour, visual hallucinations, and dilated pupils. ${ }^{2}$ There was an initial suspicion that this poison had been ingested by our two patients.

Many infections of the central nervous system may have prominent psychiatric manifestations, leading to initial misdiagnosis, psychopharmacological intervention, and delay in starting appropriate treatment. ${ }^{3-7}$

Both the young adult patients described above had pyogenic meningitis. Both developed wildly disturbed behaviour of sudden onset with clouding of consciousness but without other, more typical, features of central nervous infection such as fever or neck rigidity. In each case the primary diagnosis was substance abuse, and initial treatment was given accordingly. An important clue, however, to the true diagnosis in both was the finding of leucocytosis.

Diagnostic lumbar puncture and administration of antibiotics were delayed while cerebral computed tomography was performed. To facilitate this investigation both patients were sedated and ventilated, thus preventing further neurological assessment. There is disagreement among neurologists as to whether lumbar puncture should proceed without tomography in these circumstances. However, if an immediate scan is available then most would advocate its initial use to minimise the risk of coning.

To avoid potentially disastrous delays in treatment clinicians should be aware that bacterial meningitis can present quite atypically, with the sudden onset of severe behavioural disturbance closely mimicking substance abuse. Previously well patients presenting with acute behavioural disturbance and leucocytosis without clear evidence of substance abuse require urgent lumbar puncture and appropriate antibiotics. If immediate cerebral computed tomography is available it may be used before lumbar puncture, although the patient should be given broad spectrum antibiotics first. This is particularly important should short term ventilation be required, and antibiotic therapy should never be withheld while the results of investigations are awaited. ${ }^{8}$

1 Rischbieth RH, Thompson GN, Hamilton-Bruce A, Purdie GH, Peters JH. Acute encephalopathy following petrol sniffing in two Aboriginal patients. Clin Exp Neurol 1987;23:191-4.

2 Ellenhorn MJ, Barceloux DG. Medical toxicology: diagnosis and treatment of human poisoning. New York: Elsevier, 1988.

3 Oommen KJ, Johnson PC, Ray CG. Herpes simplex type 2 viral encephalitis presenting as psychosis. Am I Med 1982;73:445-8.

4 Thienhaus OJ, Khosla N. Meningeal cryptococcus misdiagnosed as a manic episode. Am f Psychiatry 1984;141:1459-60.

5 Misra PC, Hay GG. Encephalitis presenting as acute schizophrenia. BMJ 1971;i:532-3.

6 Schlitt M, Lakeman FD, Whitley RJ. Psychosis and simplex encephalitis. South Med f 1985;78:1347-50

7 Johannessen DJ, Wilson LG. Mania with cryptococcal meningitis in two AIDS patients. F Clin Psychiatry 1988;49:200-1.

8 Greenlee JE. Approach to diagnosis of meningitis, cerebrospinal fluid evaluation. Infect Dis Clin North Am 1990;4:583-98.

(Accepted 1 December 1992)

\title{
Guidelines for the management of asthma: a summary
}

\section{British Thoracic Society and others}

In 1990 the $B M 7$ published guidelines for the management of asthma in adults, which were the result of initiatives by the British Thoracic Society, the Research Unit of the Royal College of Physicians, the King's Fund Centre, and the National Asthma Campaign. These were produced by a group of respiratory and general physicians and general practitioners and modified after wide circulation and discussion within the British Thoracic Society. They were the first national guidelines for the management of a specific condition in the United Kingdom. These guidelines were intended to be reviewed and revised after two years. Such revision has now taken place and the opportunity has been taken to invite the British Paediatric Association and the British Paediatric Respiratory Group to include guidance for the management of asthma in children. The guidelines have also benefited from the input of the British Association for Accident and Emergency Medicine, the Royal College of Practitioners, and the General Practitioners in Asthma Group.

The revision deals with the management of asthma in both children and adults and covers new treatments not considered in 1990. It also gives clearer descriptions of what represents control of asthma, and it emphasises guided self management. The stepwise approach to managing asthma has been retained and is presented in a way that emphasises the importance of the stepping down of treatment. Mortality and morbidity from asthma are unacceptably high. Many deaths and much unnecessary morbidity have been associated with overreliance on bronchodilators, underuse of inhaled and oral corticosteroids, failure to make objective measurements of severity, and inadequate supervision. These recommendations promote greater use of inhaled anti-inflammatory drugs (even in patients with apparently mild asthma), objective monitoring of progress of asthma based on the patient's own measurements of peak expiratory flow, and greater participation of the patient or parents in the management of the condition.

The full text of the revision appears this month as a supplement of Thorax. The charts published here are a new approach providing the same information in a condensed form designed to provide the busy clinician with a quick but accurate reference guide to asthma management at the point of delivery of care. The six charts cover management of asthma in general practice, in the outpatient department, in the accident and emergency department, and on the wards. These chart guidelines are targeted at doctors and should be seen as a general framework within which most patients with asthma can be managed.

\section{PARTICIPANTS}

Asthma in adults: Professor P J Barnes, A H Barnett, R A L Brewis, P S Burge, R A Clark, D Costain, G K Crompton, S R Durham, P Ebden, B D W Harrison, J P R Hartley, S R Hilton, Professor S T Holgate, W F Holmes, A Hopkins, D J Lane, E R Neville, R Neville, R L Page, M R Partridge, M G Pearson, Professor N B Pride, M Rudolf, D E Stableforth, J G B Thurston.

Asthma in children: W Lenney, J Price, Professor J O Warner, R Clifford, R Campbell, T Liscombe, J Williams, G Russell, M Levy, P McCarthy, N Barnes, M Silverman, S MacKenzie, C Nourse. 


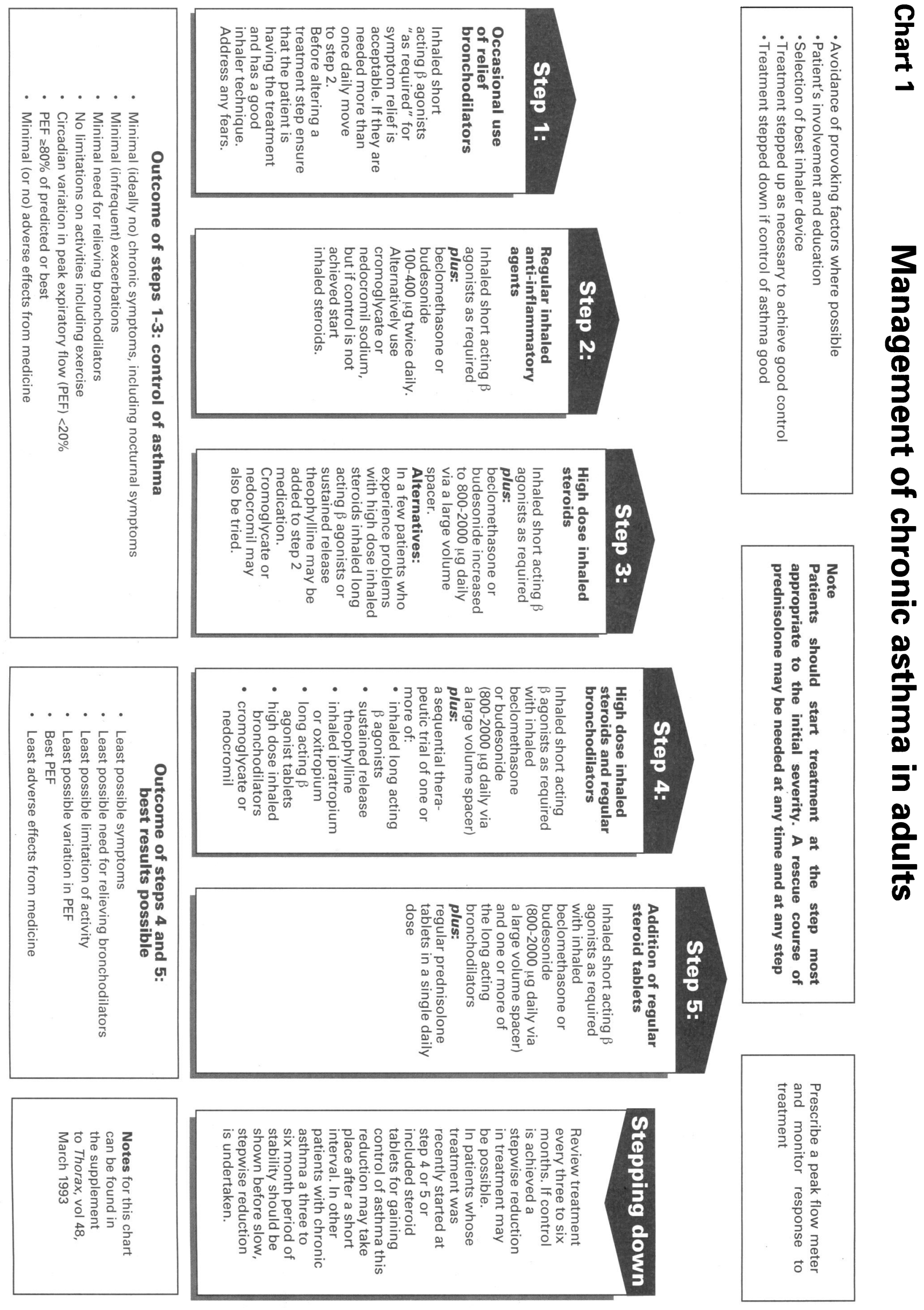

Adapted from poster designed by Business Design Group 

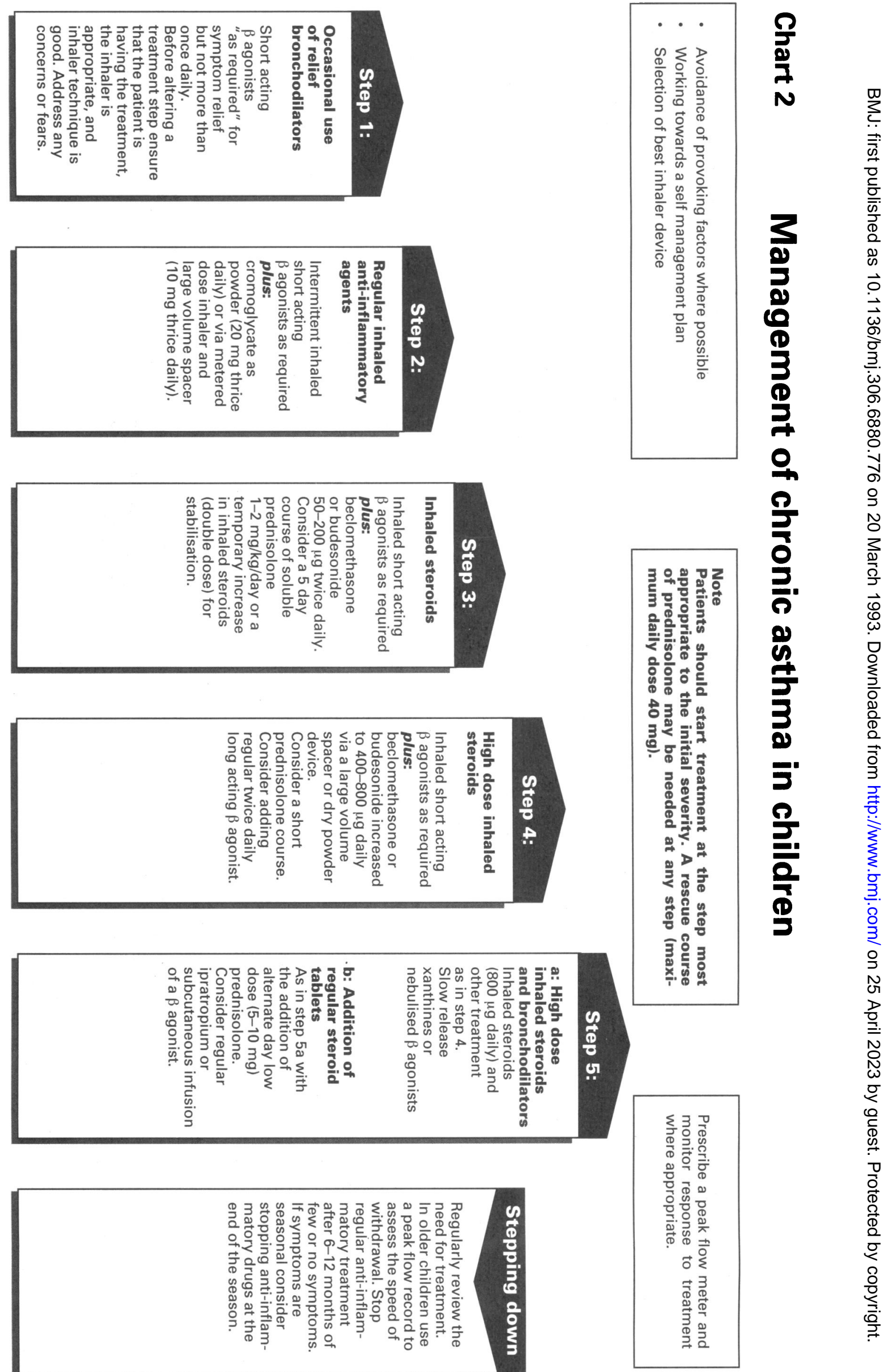

$\begin{array}{ll}0 & \text { ป } \\ 0 & 0 \\ 0 & 0\end{array}$

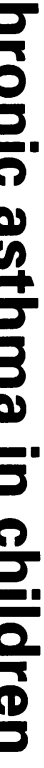

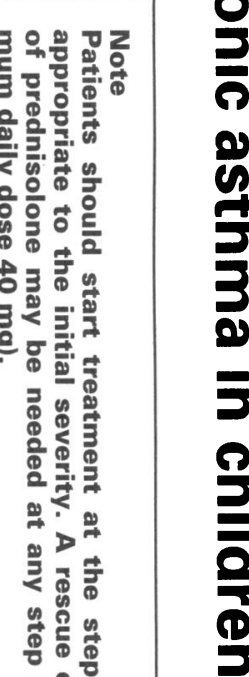

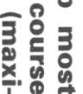

N

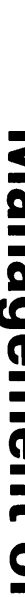

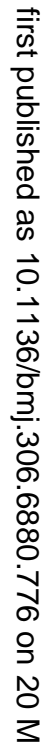

$\overrightarrow{0}$

$\mathbf{8}$

ㅇํํ

- $\overrightarrow{0}$

吾

!

욱 


\section{Acute severe asthma in adults}

\section{Recognition and assessment in hospital}

Features of acute severe asthma

- Can't complete sentences in one breath

- Respirations $\geq 25$ breaths/min

- Pulse $\geq 110$ beats/min

- Peak expiratory flow (PEF) $\leq 50 \%$ of predicted or best

\section{Life threatening features}

- PEF $<33 \%$ of predicted or best

- Silent chest, cyanosis, or feeble respiratory effort

- Bradycardia or hypotension

- Exhaustion, confusion, or coma
If a patient has any of these features, then measure arterial blood gases.

Markers of a very severe, life threatening attack:

- Normal (5-6 kPa, 36-45 mm Hg) or high $\mathrm{PaCO}_{2}$

- Severe hypoxia: $\mathrm{PaO}_{2}<8 \mathrm{kPa}(60 \mathrm{~mm} \mathrm{Hg})$ irrespective of treatment with oxygen

- A low pH (or high $\mathrm{H}^{+}$)

No other investigations are needed for immediate management.

\section{Caution:}

Patients with severe or life.threatening attacks may not

be distressed and may not have all these abnormalities.

The presence of any should alert the doctor.

1 Immediate treatment

- Oxygen $-40-60 \%\left(\mathrm{CO}_{2}\right.$ retention is not aggravated by oxygen therapy in asthma)

- Salbutamol $5 \mathrm{mg}$ or terbutaline $10 \mathrm{mg}$ via an oxygen driven nebuliser

- Prednisolone tablets 30-60 mg or intravenous hydrocortisone $200 \mathrm{mg}$, or both, if very il

- No sedatives of any kind

- Chest radiograph to exclude pneumothorax

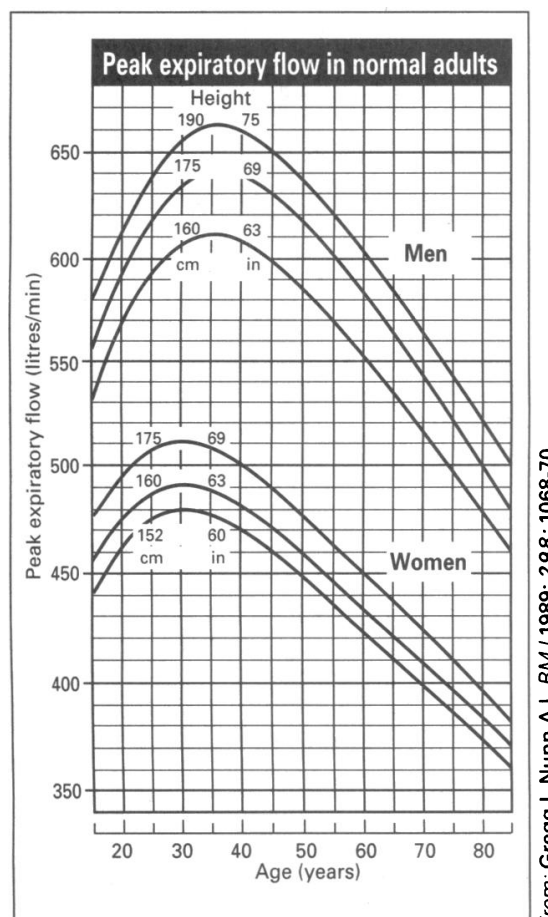

IF LIFE THREATENING FEATURES ARE PRESENT:

- Add ipratropium $0.5 \mathrm{mg}$ to the nebulised $\beta$ agonist

- Give intravenous aminophylline $250 \mathrm{mg}$ over 20 minutes or salbutamol or terbutaline $250 \mu \mathrm{g}$ over 10 minutes. Do not give bolus aminophylline to patients already taking oral theophyllines

\section{Subsequent management}

IF PATIENT IS IMPROVING CONTINUE:

- $40-60 \%$ oxygen

- Prednisolone 30-60 mg daily or intravenous hydrocortisone 200 mg every 6 hours

- Nebulised $\beta$ agonist 4 hourly

IF PATIENT IS NOT IMPROVING AFTER 15-30 MINUTES:

- Continue oxygen and steroids

- Give nebulised $\beta$ agonist more frequently, up to every $15-30$ minutes

- Add ipratropium $0.5 \mathrm{mg}$ to nebuliser and repeat 6 hourly until patient is improving

IF PATIENT IS STILL NOT IMPROVING GIVE:

- Aminophylline infusion (small patient $750 \mathrm{mg} / 24$ hours, large patient $1500 \mathrm{mg} / 24$ hours) monitor blood concentrations if it is continued for over 24 hours

- Salbutamol or terbutaline infusion as an alternative to aminophylline
3 Monitoring treatment

- Repeat measurement of PEF 15-30 minutes after starting treatment

- Oximetry: maintain $\mathrm{SaO}_{2}>92 \%$

- Repeat blood gas measurements within 2 hours of starting treatment if

- initial $\mathrm{PaO}_{2}<8 \mathrm{kPa}(60 \mathrm{~mm} \mathrm{Hg})$ unless subsequent $\mathrm{SaO}_{2}>92 \%$

- $\mathrm{PaCO}_{2}$ was normal or raised - patient deteriorates

- Chart PEF before and after giving nebulised or inhaled $\beta$ agonists and at least 4 times daily throughout hospital stay

\section{Transfer patient to the}

intensive care unit accompanied

by a doctor prepared to intubate if there is:

- Deteriorating PEF, worsening or persisting hypoxia, or hypercapnia

- Exhaustion, feeble respirations, confusion, or drowsiness

- Coma or respiratory arrest

\section{When discharged from}

hospital patients should have:

- Been on discharge medication for 24 hours and have had inhaler technique checked and recorded

- PEF $>75 \%$ of predicted or best and PEF diurnal variability $<25 \%$ unless discharge is agreed with respiratory physician

- Treatment with oral and inhaled steroids in addition to

bronchodilators

- Own PEF meter and written self management plan

- GP follow up arranged within 1 week

- Follow up appointment in respiratory clinic within 4 weeks

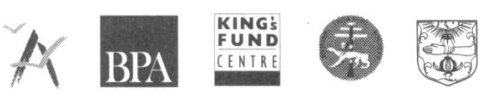




\section{Acute severe asthma in children}

\section{Recognition of acute severe asthma}

- Too breathless to talk

- Too breathless to feed

- Respirations z50 breaths/min

- Pulse $\geq 140$ beats $/ \mathrm{min}$

- PEF $\leq 50 \%$ predicted or best

Life threatening features

- $\mathrm{PEF}<33 \%$ predicted or best

- Cyanosis, a silent chest, or poor respiratory effort

- Fatigue or exhaustion

- Agitation or reduced level of consciousness
No other investigations are needed for immediate management.

Blood gas estimations are rarely helpful in deciding initial management in children.

Caution:

Children with severe attacks may not appear distressed; assessment in the very young may be difficult. The presence of any of these features should alert the doctor.

\section{Management of a severe asthma attack}

\section{Immediate treatment}

- High flow oxygen via face mask

- Salbutamol $5 \mathrm{mg}$ or terbutaline $10 \mathrm{mg}$ via an oxygen driven nebuliser (half doses in very young children)

- Prednisolone 1-2 mg/kg body weight orally (maximum $40 \mathrm{mg}$ )

IF LIFE THREATENING FEATURES ARE PRESENT:

- Give intravenous aminophylline $5 \mathrm{mg} / \mathrm{kg}$ over 20 minutes followed by maintenance infusion, $1 \mathrm{mg} / \mathrm{kg} / \mathrm{h}$; omit the loading dose if child is already receiving oral theophyllines

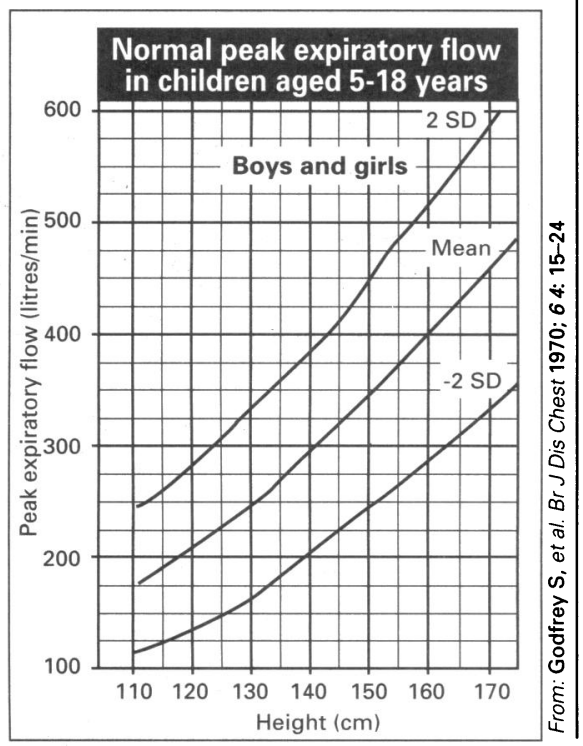

- Give intravenous hydrocortisone 100 mg 6 hourly

- Add ipratropium $0.25 \mathrm{mg}$ to nebulised $\beta$ agonist $(0.125 \mathrm{mg}$ in very young children)

- Pulse oximetry is helpful in assessing response to treatment An $\mathrm{SaO}_{2} \leq 92 \%$ may indicate the need for chest radiography.

\section{Subsequent management}

IF PATIENT IS IMPROVING CONTINUE:

- High flow oxygen

- Prednisolone 1-2 mg/kg daily (maximum $40 \mathrm{mg} / \mathrm{day}$ )

- Nebulised $\beta$ agonist 4 hourly

IF PATIENT IS NOT IMPROVING AFTER 15-30 MINUTES:

- Continue oxygen and steroids

- Give nebulised $\beta$ agonist more frequently, up to every 30 minutes

- Add ipratropium to nebuliser and repeat 6 hourly until improvement starts

IF PATIENT IS STILL NOT IMPROVING GIVE:

- Aminophylline infusion (1 mg/kg/h); monitor blood concentrations if continued for over 24 hours
3 Monitoring treatment

- Repeat PEF measurement 15-30 minutes after starting treatment (if appropriate)

- Oximetry: maintain $\mathrm{SaO}_{2}>92 \%$

- Chart PEF if appropriate before and after the child inhales $\beta$ agonists and at least 4 times daily throughout hospital stay

4 Transfer to the intensive care unit accompanied by a doctor prepared to intubate if there is:

- Deteriorating PEF or worsening or persistent hypoxia or hypercapnia

- Exhaustion, feeble respirations,

confusion, or drowsiness

- Coma or respiratory arrest

\section{When discharged from} hospital patients should

have:

- Been on discharge medication for 24 hours/and have had inhaler technique checked and recorded

- If recorded, PEF $>75 \%$ of predicted or best and PEF diurnal variability $<25 \%$

- Treatment with soluble steroid tablets and inhaled steroids in addition to bronchodilators

- Own PEF meter and if appropriate self management plan or written instructions for parents

- GP follow up arranged within 1 week

- Follow up appointment in clinic within 4 weeks 


\section{Acute severe asthma in adults in general practice}

\begin{tabular}{|c|c|}
\hline \multicolumn{2}{|c|}{ Many deaths from asthma are preventable: delay can be fatal } \\
\hline $\begin{array}{l}\text { Factors include: } \\
\text { - Doctors failing to assess severity by objective } \\
\text { measurement } \\
\text { - Patients or relatives failing to appreciate severity }\end{array}$ & $\begin{array}{l}\text { Assess and record: } \\
\text { - Symptoms and response to self treatment } \\
\text { - Heart and respiratory rates } \\
\text { - Peak expiratory flow (PEF) }\end{array}$ \\
\hline $\begin{array}{l}\text { - Underuse of corticosteroids } \\
\text { Regard each emergency consultation as for acute } \\
\text { severe asthma until it is shown otherwise. }\end{array}$ & $\begin{array}{l}\text { Caution: } \\
\text { Patients with severe or life threatening attacks } \\
\text { may not be distressed and may not have all } \\
\text { these abnormalities. The presence of any should } \\
\text { alert the doctor. }\end{array}$ \\
\hline
\end{tabular}

\section{Uncontrolled asthma \\ ASSESSMENT \\ - Speech normal \\ - Pulse $<110$ beats/min \\ - Respiration $<25$ breaths/min \\ - PEF $>50 \%$ predicted or best MANAGEMENT \\ Treat at home but response to treatment MUST be assessed before you leave \\ TREATMENT \\ Nebulised salbutamol $5 \mathrm{mg}$ or terbutaline $10 \mathrm{mg}$}

MONITOR RESPONSE 15-30 MIN AFTER NEBULISER

If PEF $>50-75 \%$ predicted or best

- Give prednisolone 30-60 mg

- Step up usual treatment

or

if PEF $>75 \%$ predicted or best

- Step up usual treatment

FOLLOW UP

- Monitor symptoms and PEF on PEF chart

- Self management plan

- Surgery review $\leq 48$ hours

- Modify treatment at review according to guidelines for chronic persistent asthma

CRITERIA FOR HOSPITAL ADMISSION

- Any life threatening features

- Any features of acute severe asthma present after initial treatment, especially PEF $<33 \%$

\section{LOWER THE THRESHOLD FOR ADMISSION IF:}

Attack is in afternoon or evening, recent nocturnal symptoms etc, recent hospital admission, previous severe attacks, patient unable to assess own condition, concern over social circumstances

\section{Acute severe asthma} ASSESSMENT

- Can't complete sentences

- Pulse $\geq 110$ beats/min

- Respiration $\geq 25$ breaths/min

- PEF $550 \%$ of predicted or best

\section{MANAGEMENT}

Seriously consider admission if more than one feature above present

TREATMENT

- Oxygen $40-60 \%$ if available

- Nebulised salbutamol $5 \mathrm{mg}$ or terbutaline $10 \mathrm{mg}$

- Prednisolone 30-60 mg or intravenous hydrocortisone $200 \mathrm{mg}$

MONITOR RESPONSE 15-30 MIN AFTER NEBULISER

If any signs of acute severe asthma persist

- Arrange admission

- Repeat nebulised $\beta$ agonist plus ipratropium $0.5 \mathrm{mg}$

or give subcutaneous terbutaline or give intravenous aminophylline (slowly) while awaiting ambulance

or

if good response to first nebulised treatment (symptoms improved,

respiration and pulse settling, and PEF $>50 \%$ ):

- Step up usual treatment and continue prednisolone

\section{FOLLOW UP}

- Monitoring of symptoms and PEF

- Self management plan

- Surgery review $\leq 24$ hours

Modify treatment at review according to guidelines for chronic persistent asthma

\section{Life threatening asthma} ASSESSEMENT

- Silent chest

- Cyanosis

- Bradycardia or exhaustion

- PEF $<33 \%$ of predicted or best

MANAGEMENT

Arrange immediate ADMISSION

TREATMENT

- Prednisolone 30-60 mg or intravenous hydrocortisone $200 \mathrm{mg}$ immediately

- Oxygen driven nebuliser in ambulance

- Nebulised $\beta$ agonist and ipratropium or subcutaneous terbutaline or intravenous aminophylline (250 mg slowly)

Stay with patient until ambulance arrives

NB If there is no nebuliser give 2 puffs of $\beta$ agonist via a large volume spacer and repeat 10-20 times

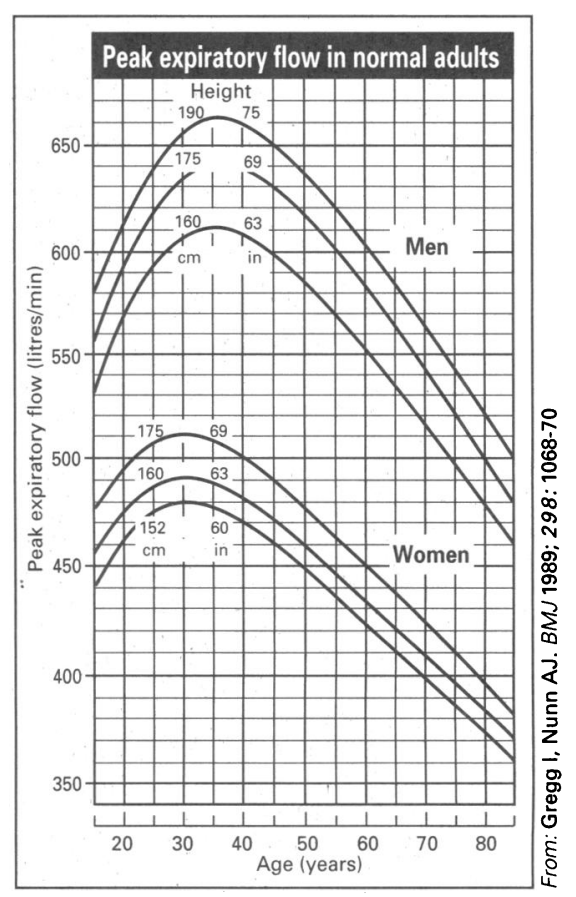




\section{Chart 6}

\section{Asthma in accident and emergency departments}

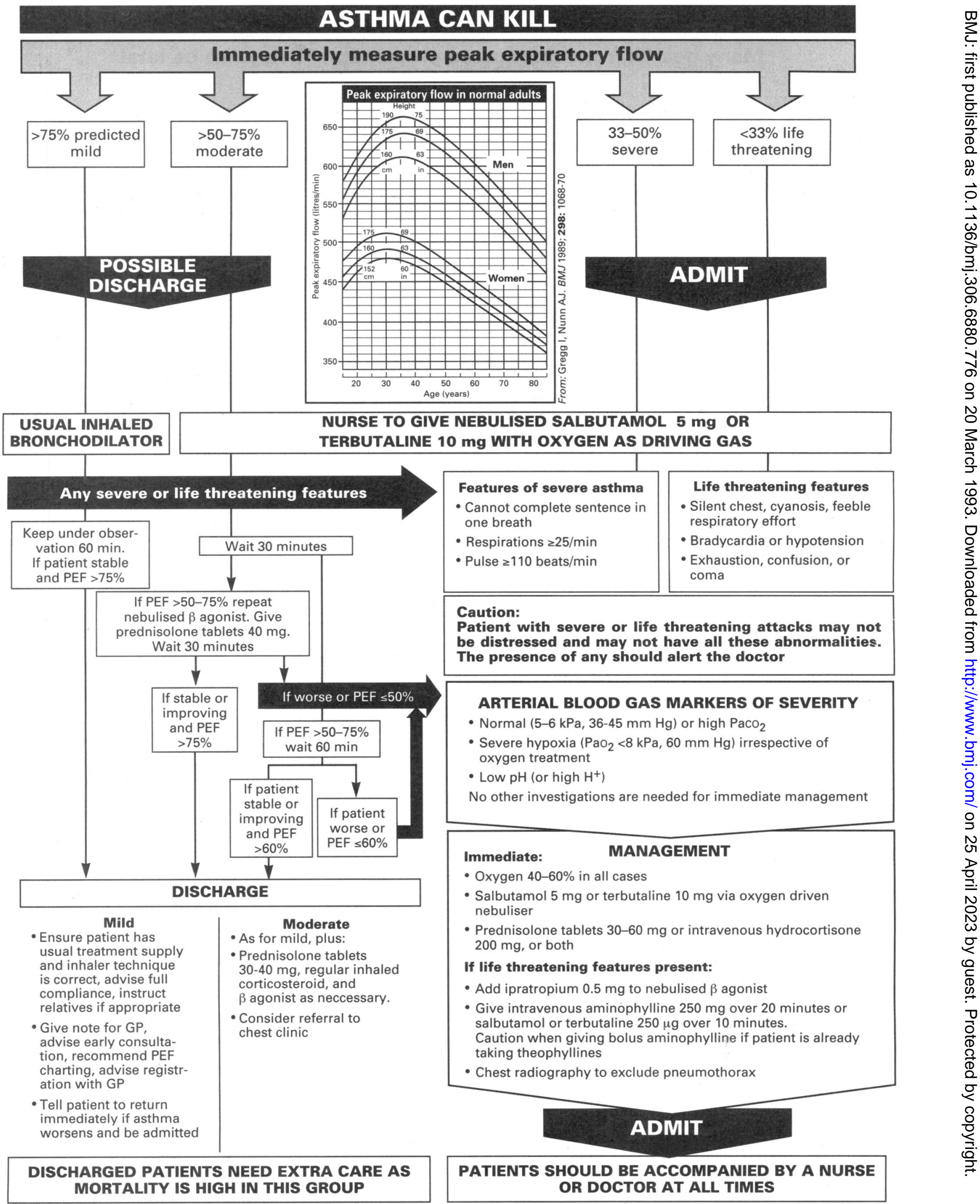

This chart is appropriate for patients from puberty onwards 